\title{
Tetanus vaccination, antibody persistence and decennial booster: a serosurvey of university students and at-risk workers
}

\author{
M. BORELLA-VENTURINI, C. FRASSON, F. PALUAN, D. DE NUZZO, \\ G. DI MASI, M. GIRALDO, F. CHIARA AND A. TREVISAN* \\ Department of Cardiologic, Thoracic and Vascular Sciences, Unit of Preventive Medicine and Risk Assessment, \\ University of Padova, Via Giustiniani 2, I-35128 Padova, Italy
}

Received 27 September 2016; Final revision 6 February 2017; Accepted 15 February 2017; first published online 15 March 2017

\section{SUMMARY}

The aim of the present research is to verify the immune status against tetanus in students and workers exposed to risk and to ascertain whether a decennial booster is necessary. Antibodies against tetanus were measured in 1433 workers and students of Padua University (Italy). The enrolment criterion was the ability to provide a booklet of vaccinations released by a public health office. The influence of age, gender, the number of vaccine doses, and the interval since the last dose was determined. Ten years after the last dose, the majority of subjects $(95 \cdot 0 \%)$ displayed an antibody titre above the protective level $(\geqslant 0 \cdot 10 \mathrm{IU} / \mathrm{ml})$, and half of these $(49 \cdot 1 \%)$ had a long-term protective level $(\geqslant 1.0 \mathrm{IU} / \mathrm{ml})$. According to our data, titre depends on both the number of vaccine doses and the interval since the last dose $(P<0 \cdot 0001)$. Five vaccine doses and an interval of at least 10 years since the last dose are predictive of a long-term protective titre in absence of a booster $(1.97 \mathrm{IU} / \mathrm{ml})$. These data suggest that when primary series are completed, a decennial booster is unnecessary for up to 20 years. Furthermore, we recommend measuring the antibody level before a new booster is given to prevent problems related to over-immunisation.

Key words: Antibody titre, booster, tetanus, vaccination.

\section{INTRODUCTION}

Tetanus is a severe, non-contagious infectious disease caused by Clostridium tetani, which is ubiquitous in the environment. Its spores are introduced through wounds contaminated with soil, dust or faeces. Other routes of infection include lacerations, burns or minor scratches; injection drug use and surgical procedures may be additional sources of infection [1]. Neonatal tetanus is a possible cause of mortality

\footnotetext{
* Author for correspondence: Prof. A. Trevisan, Department of Cardiologic, Thoracic and Vascular Sciences, Unit of Preventive Medicine and Risk Assessment, University of Padova, Via Giustiniani 2, I-35128 Padova, Italy.

(Email: andrea.trevisan@unipd.it)
}

in the first month of life, especially in developing countries [2].

Tetanus, Lyme disease, tick-borne encephalitis, hepatitis A, hepatitis E and anthrax are the most common biological risks for workers outside of healthcare units. Since 1963 (Law 292/63), vaccination against tetanus has been mandatory in Italy for professional categories such as farmers, metal workers, livestock breeders and waste workers as well as children during their second year (since 1968, vaccination has been required within the first year of age). Moreover, vaccination has been mandatory since 1938 for military personnel, explaining the higher incidence of tetanus among women in the past [3]. This is only mandatory vaccination for workers in Italy. 
The tetanus vaccination schedule consists of a primary series (three doses) at the third, fifth and 11th months of age (mandatory), two boosters at 6 and 11-15 years of age, and one booster every 10 years (recommended) in the form of a combined tetanusdiphtheria (mandatory) or tetanus-diphtheria-acellular pertussis (recommended) vaccine. This strategy is similar to that adopted in other countries of the European Union and in the USA, and is generally considered to be highly effective in preventing tetanus, providing 95\% protection to vaccine recipients [4].

The need for a decennial booster after five doses is a topic of debate, above all because the excessive use of boosters could result in severe side effects [5] such as the Arthus phenomenon and allergic or systemic reactions. It is thought that these side effects are associated with the administration of a large number of doses over a short period of time, which was recommended practice in the 1950s; no instance of adverse effects has been published over the last 25 years [6].

The incidence of tetanus in Italy is lower than 1 case/1 $000000 /$ year [3] but is higher than that reported in other European countries [7]. The incidence of tetanus infection is high in the elderly, particularly among elderly women [3].

The aim of the present study was to verify the persistence of protective antibody level after vaccination in order to determine whether the decennial booster is necessary. The influence of gender, age, the number of vaccine doses and the interval since the last dose on antibody titre was evaluated.

\section{METHODS}

\section{Study design}

According to the European Community (CEE directive 90/679) and Italian legislative decree 81/08, our unit submits all university workers and students to health surveillance. Among workers, subjects employed prevalently in the Agricultural, Engineering, Veterinary and Archaeology School of Padua University (1433 in total; 553 males and 880 females), as well as those in all departments with possible contact with soil, animals or waste who are required to be vaccinated, were examined between 2004 and 2011 for tetanus antibody titre according to health protocols established for our study.

The inclusion criteria were to have been born in Italy (to standardise the vaccination schedule) and to produce a booklet of vaccination released by a public health office.
Gender, age, the number of vaccine doses and the interval since the last dose were the independent variables considered in the study, whereas the antibody titre was the dependent variable.

All subjects agreed to the anonymous treatment of their personal data and signed a consent form. The research was based on data available due to health surveillance according to the law; the approval of the study by an ethics committee was not therefore required.

\section{Analytical methods}

The IgG-class of antibodies against Clostridium tetani toxin was measured in serum using the EIA (Enzyme Immune Assay) method (Radim, Rome, Italy). A tetanus antitoxin titre $\geqslant 0.1 \mathrm{IU} / \mathrm{mL}$ is conventionally presumed to be protective (Centre for Disease Prevention and Control (CDC), 2006). In addition, a poor but sufficient protective level is defined to range from 0.11 to $0.5 \mathrm{IU} / \mathrm{mL}$ and a good protective level from 0.51 to $<1 \mathrm{IU} / \mathrm{mL}$; a long-lasting protective level is defined as $\geqslant 1.0 \mathrm{IU} / \mathrm{mL}$ [8]. This method does not measure values higher than $5 \mathrm{IU} / \mathrm{ml}$, which is used as the upper bound.

\section{Statistical analysis}

Characteristics of the subjects and antibody titre were compared using parametric (unpaired $t$ test) and nonparametric (Mann-Whitney) tests. The $\chi^{2}$ test was applied to compare frequency distributions (Yates correction). Simple and multiple linear regression models and the prediction of multiple regressions were performed to identify associations between antibody titre (dependent variable) and age, gender, dose number and interval since the last dose (independent variables). The Cuzik trend test was utilised to evaluate the influence of dose number and interval since the last dose on the antibody titre. The subjects were categorised according to the number of doses (less than five, five and more than five) and the interval since the last dose ( $<5$ years, $6-10$ years, $11-15$ years and $>15$ years). StatsDirect 2.7.7 (StatsDirect Ltd, UK) was used for all statistical analyses.

\section{RESULTS}

Subjects ranged in age from 18 to 64 years (Table 1), and the female subjects were on average significantly younger than males $(P<0 \cdot 0001)$. Seventy-two of the 
Table 1. Age, number of vaccine doses, interval (years) since the last vaccine dose or booster, and antibody titre against tetanus toxin in the subjects enrolled in the study

\begin{tabular}{llllll}
\hline \hline & No. & Age & No. of doses & Years since the last dose & Antibody (IU/mL) \\
\hline All subjects & 1433 & $23 \cdot 9 \pm 5 \cdot 4(18-64)$ & $5 \cdot 0 \pm 0 \cdot 9(3-9)$ & $10 \cdot 0 \pm 6 \cdot 3(0-35)$ & $0 \cdot 97(0 \cdot 01->5 \cdot 0)$ \\
Males & 553 & $24 \cdot 8 \pm 6 \cdot 9(18-64)^{*}$ & $5 \cdot 1 \pm 0 \cdot 9(3-9)$ & $9 \cdot 9 \pm 6 \cdot 2(0-31)$ & $1 \cdot 15(0 \cdot 01->5 \cdot 0)$ \\
Females & 880 & $23 \cdot 3 \pm 4 \cdot 0(18-49)$ & $5 \cdot 0 \pm 0 \cdot 9(3-9)$ & $10 \cdot 1 \pm 6 \cdot 3(0-35)$ & $0 \cdot 96(0 \cdot 01->5 \cdot 0)$ \\
\hline \hline
\end{tabular}

The results are reported as the mean values \pm s.D. (range) according to age, dose number and interval since the last dose; the median is given for antibody titre.

* Males vs. females: $P<0 \cdot 0001$.

subjects $(5 \cdot 0 \%)$ had an antibody titre below the supposed protective level of $0 \cdot 1 \mathrm{IU} / \mathrm{mL}$, while 254 $(17 \cdot 7 \%)$ appeared to be poorly protected. None of these subjects took immunosuppressive drugs. The majority $(1107,77 \cdot 3 \%)$ had good $(404,28 \cdot 2 \%)$ or long-lasting $(703,49 \cdot 1 \%)$ protective titres. No difference was observed in antibody titre according to gender; thus, further evaluations were made without taking into account the gender of the subject.

The majority of subjects $(50 \%)$ completed the five-dose vaccination schedule, whereas $24.5 \%$ were vaccinated with fewer than five doses (range 3-4 doses) and $25.5 \%$ with more than five doses (range 6-9 doses). As expected, dose number significantly $(P<0.0001)$ influenced antibody titre (Fig. 1). In fact, a poor but protective titre $(0.37 \mathrm{IU} / \mathrm{mL}, 0.05-$ 0.96 on 355 subjects) persists for over 15 years (Fig. 2); in support of this, further analysis revealed that the majority of individuals with an interval longer than 10 years since the last dose displayed a protective titre unless they did not receive a booster (Table 2). Moreover, multiple linear regression predicted that five doses and 10 years since the last dose are predictive of an antibody titre of $1.99 \mathrm{IU} / \mathrm{mL}$. Surprisingly, $4.5 \%$ of subjects meeting these criteria did not complete the primary vaccination schedule. Indeed, trend analysis confirms a significant influence of neither dose number nor interval since the last dose on antibody titre $(P<0.0001)$. The absence of protection (antibody titre below $0 \cdot 1 \mathrm{U} / \mathrm{ml}$ ) was consistently inversely correlated with both the number of doses and the time since the last dose (Table 3 ): $3 \cdot 1 \%$ of individuals receiving five doses and $14.2 \%$ of those with fewer than five doses were not protected, and the number of nonprotected individuals increased from $5 \cdot 8 \%$ to $16 \cdot 1 \%$ after 15 years. All but one of these subjects fall into the range time after last dose of more than 10 years. These data suggest that the majority of individuals that did not receive a booster 10 years after the last dose remained protected for at least 15 years. Using

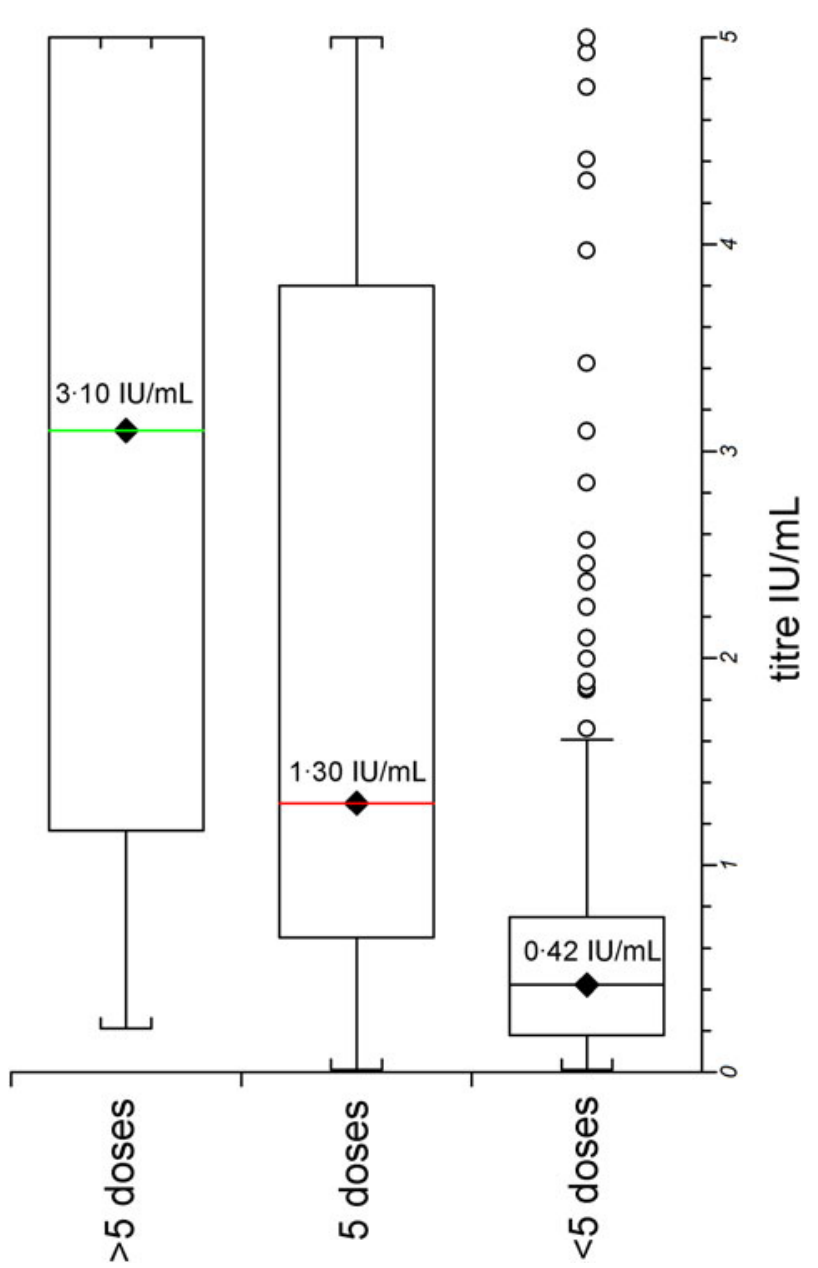

Fig. 1. Comparison among different doses of vaccine administered during the subjects' lifetimes. All compared regimens exhibited a highly significant difference $(P<$ 0.0001, two-sided, Mann-Whitney). Lines and diamonds in the box indicate medians, the edges of the boxes indicate quartiles, and the circles indicate fence values to define outliers for each dataset, as calculated by a statistics programme.

regression analyses, it was possible to establish a halflife of antibody titre of 10 years followed by a loss of the protective titre after $19 \cdot 7$ years. Finally, multivariate analysis suggests that gender could influence 


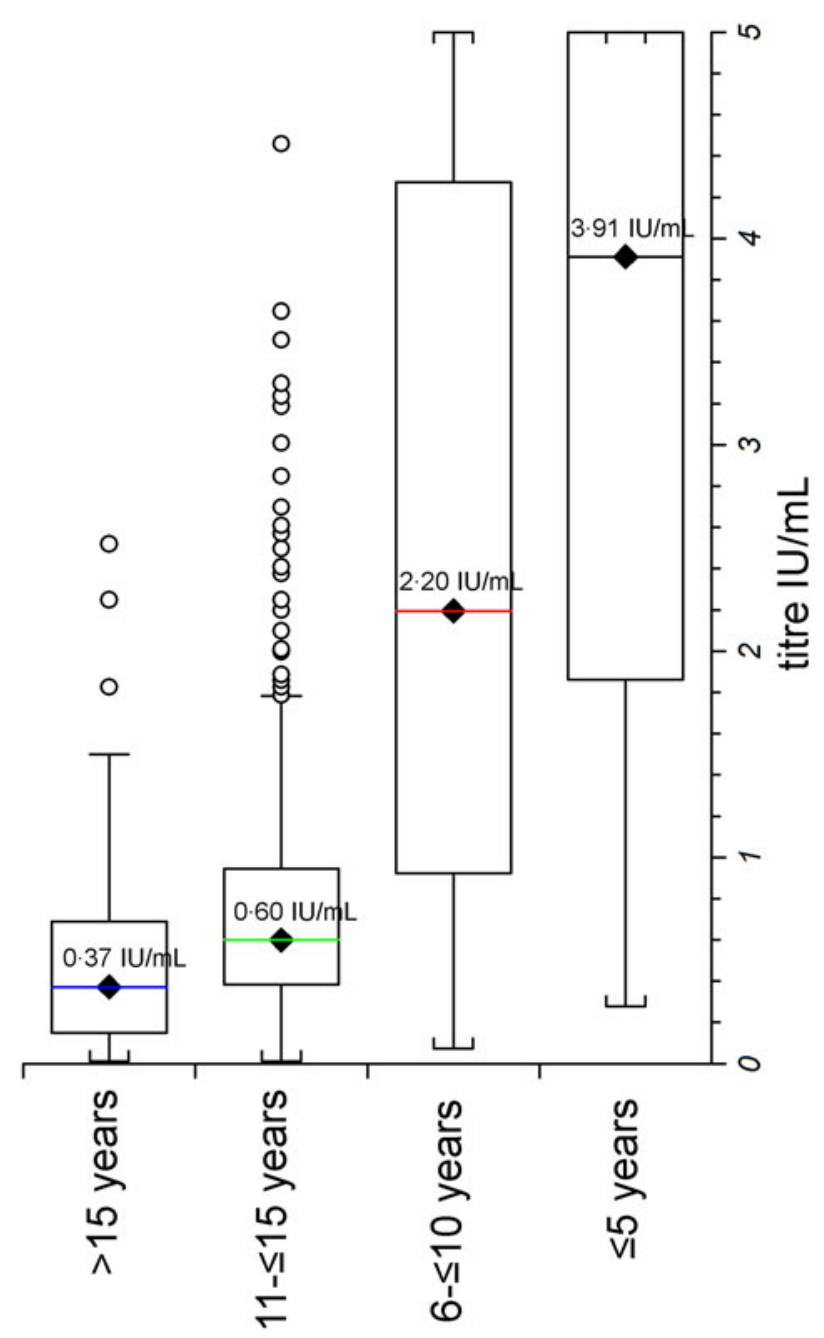

Fig. 2. Comparison among different intervals since the last vaccine dose. All compared intervals exhibited a highly significant difference $(P<0.0001$, two sided, MannWhitney). Lines and diamonds in the box indicate medians, the edges of the boxes indicate quartiles, and the circles indicate fence values to define outliers for each dataset, as calculated by a statistics programme.

antibody titre $(P=0.0268)$, despite the absence of significance based on single variable comparison.

\section{DISCUSSION}

The goal of the present research was to investigate protection against tetanus among university workers exposed to this specific risk. In particular, we aimed to ascertain whether the decennial booster of tetanus vaccine recommended by CDC [9] and in Italy by the National Vaccine Plan 2016-2018 is necessary to maintain a protective antibody titre throughout life because it was demonstrated that immunological memory is persistent [10]. Among vaccine-preventable diseases, tetanus is infectious but not contagious; thus, vaccination does not contribute to herd immunity but rather is necessary as a personal preventive measure.

The results of the present study indicate that (i) after the primary vaccine series (three doses and two boosters at 6 and 11-15 years of age), the antibody titre persists at protective levels for a period in excess of 10 years and that (ii) vaccine doses influence antibody titre when categorised according to the interval since the last dose. For instance, we found that more than five doses guarantee a high antibody titre on average and that five vaccine doses are predictive of an antibody titre higher than $1 \mathrm{IU} / \mathrm{mL}$ at 15 or more years since the last dose. Indeed, according to our data, five doses are sufficient to maintain a protective titre for more than 15 years. This is consistent with the current knowledge that the titre half-life is 10 years and the drop to a non-protective level occurs after 20 years. We found that $11.9 \%$ of all individuals (71 of 596) aged $>10$ years had titres below levels considered protective. The percentage of non-protected individuals inversely correlates with the titre and directly correlates with the time since the last dose: $5.8 \%$ belong to the category included between 10 and 15 years, and $16 \cdot 1 \%$ received the last dose more than 15 years ago. This indicates that the five-dose vaccination schedule works very well and maintains responsiveness for at least 15 years; thus, 1 or 2 boosters every 15 years could be sufficient to maintain a lifelong protective titre.

Several authors have correlated antibody titre with the age of the subject analysed. Alternatively, we suggest that the best parameter to predict tetanus reactivity is the time since the last dose when the vaccination schedule of five doses has been completed [11-14]. Other authors state that the reactogenicity of the tetanus vaccine is greater in young subjects and women [15], while the elderly are highly seroprotected; thus, a single booster for secondary immunisation should be sufficient [16]. This is a different point of view that contrasts with the common opinion that advanced age increases risk [3]. Our results do not support an involvement of gender in the waning of antibodies against tetanus, but they definitely indicate that in the absence of boost after 10 years from the last dose, aged people became susceptible (non-protected) subjects.

Recently [17], it has been suggested, according to the half-life of tetanus antibodies calculated at 14 years, that the decennial booster schedule should be changed to a schedule of two boosters delivered at 
Table 2. Comparison of antibody titre according to number of vaccine doses and the interval since the last dose

\begin{tabular}{|c|c|c|c|c|}
\hline No. doses & $\begin{array}{l}\text { Interval since the } \\
\text { last dose }\end{array}$ & No. & $\begin{array}{l}\text { Titre IU/mL median } \\
\text { (range) }\end{array}$ & Significance \\
\hline \multirow[t]{4}{*}{$<5$} & $\leqslant 5$ years & 17 & $1 \cdot 85(0 \cdot 37->5)$ & \\
\hline & $6-\leqslant 10$ years & 12 & $1 \cdot 00(0 \cdot 37-4 \cdot 93)$ & \\
\hline & $11-\leqslant 15$ years & 116 & $0 \cdot 51(0 \cdot 01-2 \cdot 85)$ & \\
\hline & $>15$ years & 206 & $0 \cdot 31(0 \cdot 01-2 \cdot 25)$ & \\
\hline \multirow[t]{4}{*}{5} & $\leqslant 5$ years & 209 & $3 \cdot 78(0 \cdot 38->5)$ & $v s .<5$ doses: $P=0.0074$ \\
\hline & $6-\leqslant 10$ years & 267 & $2 \cdot 21(0 \cdot 07->5)$ & $v s .<5$ doses: $P=0.237$ \\
\hline & $11-\leqslant 15$ years & 102 & $0 \cdot 65(0.04-4 \cdot 46)$ & $v s .<5$ doses: $P=0.0005$ \\
\hline & $>15$ years & 138 & $0 \cdot 47(0 \cdot 01-2 \cdot 52)$ & $v s .<5$ doses: $P=0.0045$ \\
\hline \multirow[t]{4}{*}{$>5$} & $\leqslant 5$ years & 189 & $4 \cdot 28(0 \cdot 28->5)$ & $\begin{aligned} \text { vs. }<5 \text { doses: } P & =0.0015 \\
\text { vs. } 5 \text { doses: } P & =0.357\end{aligned}$ \\
\hline & $6-\leqslant 10$ years & 143 & $2 \cdot 23(0 \cdot 24->5)$ & $\begin{array}{c}\text { vs. }<5 \text { doses: } P=0 \cdot 127 \\
\text { vs. } 5 \text { doses: } P=0 \cdot 370\end{array}$ \\
\hline & $11-\leqslant 15$ years & 23 & $1 \cdot 08(0 \cdot 47-3 \cdot 51)$ & $\begin{array}{c}\text { vs. }<5 \text { doses: } P<0.0001 \\
\text { vs. } 5 \text { doses: } P=0.002\end{array}$ \\
\hline & $>15$ years & 11 & $0 \cdot 67(0 \cdot 21-1 \cdot 10)$ & $\begin{array}{r}\text { vs. }<5 \text { doses: } P=0.0032 \\
\text { vs. } 5 \text { doses: } P=0.0451\end{array}$ \\
\hline
\end{tabular}

Statistical analysis was performed with non-parametric Mann-Whitney test.

Table 3. Frequency of subjects with a titre below the protective level $(0 \cdot 1 \mathrm{IU} / \mathrm{mL})$, according to dose number (panel $A$ ) and interval since the last dose (panel B)

\begin{tabular}{lll}
\hline \hline Doses & Frequency & Per cent \\
\hline$<5$ & 50 of 351 & $14 \cdot 2$ \\
5 & 22 of 716 & $3 \cdot 1$ \\
$>5$ & 0 of 366 & \\
Interval & Frequency & Per cent \\
$\leqslant 5$ years & 0 of 415 & \\
$6-\leqslant 10$ years & 1 of 422 & $0 \cdot 2$ \\
$11-\leqslant 15$ years & 14 of 241 & $5 \cdot 8$ \\
$>15$ years & 57 of 355 & $16 \cdot 1$ \\
\hline \hline
\end{tabular}

30 and 60 years of age. Our results indicate a half-life shorter than that estimated by these authors. Thus, we propose that countries with recommendations for decennial boosters should drop these in favour of longer intervals such as those now recommended in the UK, Australia and New Zealand. These findings confirm 50 years later both the observation of Edsall et al. [5] in children and the theoretical approach of Gottlieb et al. [18], establishing that approximately $55 \%$ of the population who have previously been immunised with tetanus vaccine and who have not received an intervening booster dose within the past 14 to 21 years will have a circulating antibody titre of $0.1 \mathrm{IU} / \mathrm{mL}$ or greater. In agreement with these positions, our report shows that a decennial booster should not be routinely administered because antibody titre persists at protective levels for a longer period, especially after five doses of the vaccine.

The limits of this evaluation are primarily environmental, since people with a waning titre may not have been exposed to tetanus toxin. Regarding the university workers, who are more likely to be exposed to tetanus, we recommend (i) to test whether antibodies have waned before giving a booster dose, provided that a rapid and affordable test becomes available [19]; and (ii) to deliver a booster vaccination to those not protected, those who received the last dose at least 15 years ago, and those coming from extraEuropean countries where the vaccination plan is not implemented or the vaccination coverage is poor.

\section{DECLARATION OF INTEREST}

None.

\section{REFERENCES}

1. Centers for Disease Control and Prevention. Tetanus among injecting-drug users-California, 1997. Morbidity and Mortality Weekly Report 1998; 47(8): 149-151.

2. Bennett $\mathbf{J}$, et al. Bundling, a newly identified risk factor for neonatal tetanus: implications for global control. International Journal of Epidemiology 1996; 25: 879-884.

3. Filia A, et al. Tetanus in Italy 2001-2010: a continuing threat in older adults. Vaccine 2014; 32: 639-644. 
4. Yildirim RC, et al. Tetanus IgG antibody levels in children aged 12 to 47 months in Turkey. American Journal of Infection Control 2001; 29: 120-124.

5. Edsall G, et al. Excessive use of tetanus toxoid boosters. The Journal of the American Medical Association 1967; 202: 111-113.

6. National Advisory Committee on Immunization (NACI). Interval between administration of vaccines against diphtheria, tetanus, and pertussis. Canada Communicable Disease Report 2005; 31(ACS-9): 17-22.

7. European Centre for Disease Prevention and Control. Annual epidemiological report 2012. Reporting on 2010 surveillance data and 2011epidemic intelligence data. Stockholm: ECDC; 2013. (http://ecdc.europa.eu/ en/publications/Publications/Annual-EpidemiologicalReport-2012.pdf).

8. Chatchatee $\mathbf{P}$, et al. Seroprevalence of tetanus antibody in the Thai population: a national survey. Asian Pacific Journal of Allergy and Immunology 2007; 25: 219-223.

9. Centers for Disease Control and Prevention. Preventing tetanus, diphtheria, and pertussis among adolescents: use of tetanus toxoid, reduced diphtheria toxoid and acellular pertussis vaccines. Recommendations of the Advisory Committee on Immunization Practices (ACIP) Morbidity and Mortality Weekly Report 2006; 55(RR-03): 1-34.

10. World Health Organization. Tetanus vaccine: WHO position paper. The Weekly Epidemiological Record 2006; 81: 198-208.
11. Coulibaly N, De Serres G. Couverture vaccinale antitétanique des adultes au Canada-année 2002. Canadian Journal of Public Health 2004; 95: 456-459.

12. Maple PAC, et al. Immunity to diphtheria and tetanus in England and Wales. Vaccine 2001; 19: 167-173.

13. Schatz D, et al. Aging and the immune response to tetanus toxoid: diminished frequency and level of cellular immune reactivity to antigenic stimulation. Clinical and Diagnostic Laboratory Immunology 1998; 5: 894-896.

14. Peel MM, et al. Relationship between lymphocyte response to tetanus toxoid and age of lymphocyte donor. The Journal of Hygiene 1978; 80: 259-265.

15. Bayas JM, et al. Immunogenicity and reactogenicity of the adult tetanus-diphtheria vaccine. How many doses are necessary? Epidemiology and Infection 2001; 127: 451-460.

16. Hüllstrung HD, et al. Tetanus immunisation in geriatric patients with accidental wounds: how much is needed? Swiss Medical Weekly 2003; 133: 227-232.

17. Hammarlund E, et al. Durability of vaccine-induced immunity against tetanus and diphtheria toxins: a crosssectional analysis. Clinical Infectious Diseases 2016; 62: $1111-1118$

18. Gottlieb S, et al. (1964) Long-term immunity to tetanus - a statistical evaluation and its clinical implications. American Journal of Public Health Nation Health 1964; 54: 961-971.

19. Chithra A, et al. Role of rapid tetanus antibody test in accident and emergency department. Journal of Maxillofacial and Oral Surgery 2015; 14: 784-788. 